\title{
flaA mRNA transcription level correlates with Helicobacter pylori colonisation efficiency in gnotobiotic piglets
}

\author{
R. MANKOSKI, T. HOEPF, S. KRAKOWKA and K. A. EATON \\ Department of Veterinary Biosciences, Ohio State University, 1925 Coffey Road, Columbus, OH 43210, USA
}

\begin{abstract}
In-vivo passage of the gastric pathogen Helicobacter pylori in gnotobiotic piglets results in a greater colonisation efficiency in subsequent infections. The rate of colonisation steadily increases with the number of passages. To determine if this increased efficiency is related to the level of expression of $\mathrm{faA}$, a gene which encodes the major subunit of flagella, this study evaluated the level of $\boldsymbol{f l a} A$ expression at five points during serial invivo passage of strain 26695 . Semi-quantitative reverse transcriptase polymerase chain reaction and Northern dot-blot analysis of $\mathrm{fla} A \mathrm{mRNA}$ levels (expressed as a ratio to the level of ureA mRNA) revealed a positive correlation between flaA expression and colonisation efficiency; $f l a A$ mRNA levels increased incrementally with in-vivo passage as did colonisation rates. Immunoblots of outer-membrane vesicles from pig-passaged and laboratory-passaged strains also demonstrated marked differences in the amount of flagellin present in poor and efficient colonisers.
\end{abstract}

\section{Introduction}

Helicobacter pylori, a common human pathogen, is a gram-negative, spiral shaped, micro-aerophilic organism that inhabits gastric mucosa. It is the causative agent of chronic superficial gastritis and is implicated in gastric and duodenal ulceration [1]. H. pylori is uniquely adapted to life in the gastric mucus. Its ability to colonise mucus is most likely due, at least in part, to strong flagellar motility. It has been shown that gene products specifically associated with motility are essential for colonisation. An insertional mutation in the flaA gene, which encodes the major subunit of flagella, severely hinders colonisation of gnotobiotic piglets or ferrets by Helicobacter spp. and a mutation in $f a B$ decreases colonisation of piglets $[2,3]$.

It has been observed that in the gnotobiotic piglet model, serial in-vivo passage results in a dramatic increase in colonisation efficiency of the parent strain, human isolate 26695 [4]. Because we and others have demonstrated the importance of FlaA in colonisation $[2,3]$, this study was undertaken to determine if a correlation exists between the colonisation rate of

Received 11 June 1998; revised version accepted 7 August 1998.

Corresponding author: Dr K. A. Eaton (e-mail: eaton.1@osu. edu).
H. pylori as it is passed in vivo and the transcriptional level of flaA. The publication of the genomic sequence for strain 26695 [5] and our experience with this strain in numerous gnotobiotic piglet studies prompted the choice of strain 26695 as the experimental organism.

\section{Materials and methods}

\section{Animals and organisms}

Gnotobiotic piglets were infected orally with $2 \mathrm{ml}$ of human isolate 26695 at a titre of $10^{9} \mathrm{cfu} / \mathrm{ml}$. For quantification of colonisation efficiency, data from several different isolates were used for each pigpassage number and piglets were killed 28 days after inoculation [4]. One half of each stomach was placed in a sterile petri dish and gastric mucosa was removed with a sterile scalpel blade, weighed and homogenised in $5 \mathrm{ml}$ of Brucella broth. Ten-fold serial dilutions from $10^{1}-10^{4}$ were plated in duplicate on Trypticase Soy Agar plates supplemented with sheep blood 5\% (Becton Dickinson, Cockeysville, MD, USA) and incubated at $37^{\circ} \mathrm{C}$ under micro-aerobic conditions. Colonies were counted after 4-6 days and colonisation efficiency was determined by dividing the number of colonies obtained by the weight of the mucosa (cfu/g of mucosa). Recovered bacteria were stored in Brucella broth with glycerol $15 \%$ at $-70^{\circ} \mathrm{C}$ until used for ensuing infections or RNA isolations. All experiments 
involving piglets were approved by the OSU Laboratory Animal Care and Use Committee.

\section{Outer-membrane proteins}

Outer-membrane proteins (OMPs) of the laboratorypassaged strain 26695 and one of its pig-passaged derivatives (passaged $>11$ times) were isolated by the method of Blaser et al. [6]. Two-dimensional gel electrophoresis with equal amounts of OMPs was performed in the Mini-Protean system according to the manufacturer's instructions (BioRad, Hercules, CA, USA). Resultant gels were then either silver-stained or proteins were immobilised on uncharged nylon membranes. Flagellins were identified by immunoblotting with a monoclonal antibody which cross-reacts with FlaA and FlaB (72c, kindly donated by Dr Trevor Trust) [7].

\section{Estimation of flaA $m R N A$}

To assess the amount of flaA mRNA present in isolates of strain 26695 frozen stocks of bacterial strains were cultured on blood-agar plates and total RNA was isolated with TRIzol reagent (Gibco-BRL, Gaithersburg, MD, USA). The isolates used in this study included the laboratory-passaged human isolate (p0), an isolate which had been passaged once in germ-free piglets ( $\mathrm{p} 1$ ), one which had been passaged 11 times (p11), one which had been passaged between 11 and 20 times $(11<\mathrm{p}<20)$, and one which had been passaged $>20$ times $(\mathrm{p}>20)$.

Reverse transcriptase polymerase chain reaction (RT$P C R)$. Total RNA $(1 \mu \mathrm{g})$ was treated with amplification grade DNAase and reverse transcribed with Superscript RNAse $\mathrm{H}^{-}$Reverse Transcriptase (Gibco$\mathrm{BRL}$ ) and random hexamers to prime cDNA synthesis. Reverse transcription reactions without Superscripts were also included to ensure that subsequent amplification products were not the result of undigested DNA. Two $\mu \mathrm{l}(10 \%)$ of the cDNA preparations were amplified in a multiplex PCR with 100-pmols of the following primers: $f l a A$, 5'-ATGGCTTTTCAGGTCAATAC-3' and $5^{\prime}$-GCCTTAAGATATTTTGTTGAACG-3' [8]; and ure $A, 5^{\prime}$-GCCAATGGTAAATTAGTT$3^{\prime}$ and 5'-CTCCTTAATTGTTTTTAC-3' [9]. Amplifications were performed in a $100-\mu l$ volume with a model 480 thermocycler (Perkin-Elmer, Norwalk, CT, USA) under the following conditions: $1 \times$ PCR buffer, $0.8 \mathrm{mM}$ dNTPs, $1.5 \mathrm{mM} \mathrm{MgCl}_{2}, 2.5 \mathrm{U}$ of Taq polymerase; $3 \mathrm{~min}$ incubation at $94^{\circ} \mathrm{C}$ followed by 28 cycles of $94^{\circ} \mathrm{C}$ for $1 \mathrm{~min}, 50^{\circ} \mathrm{C}$ annealing for $1 \mathrm{~min}$ and $72^{\circ} \mathrm{C}$ for $2 \mathrm{~min}$. The reaction was then extended by a further $10 \mathrm{~min}$ at $72^{\circ} \mathrm{C}$ (all reagents from Gibco-BRL). Fifteen $\mu \mathrm{l}$ of the reaction products were analysed on agarose $1 \%$ gels stained with ethidium bromide. Gels were digitised on a Gelprint 2000i (BioPhotonics, Ann Arbor, MI, USA) and band intensities were quantified with ImageQuant software (Molecular Dynamics,
Sunnyvale, CA, USA). Corrections were made to compensate for the difference in size between the flaA and ure $A$ amplicons by dividing their intensities by their respective number of base pairs. Two separate batches of RNA were derived for analysis by PCR. From these samples, a total of three reverse transcription reactions and four amplification reactions were performed.

Northern blot analysis. Total RNA was isolated and treated with DNAase as above, extracted with phenol/ chloroform and precipitated with $3 \mathrm{M}$ sodium acetate (pH 5) and ethanol; $100 \mathrm{ng}$ of each RNA preparation were amplified with the $f l a A$ primers as above for 35 cycles to ensure that no endogenous DNA was present in the samples. Total RNA from each of the five isolates used in this study was diluted to $280 \mathrm{ng} / \mu \mathrm{l}$ and each sample was five-fold serially diluted to a final concentration of $c .2 \mathrm{ng} / \mu \mathrm{l}$. Two $\mu \mathrm{l}$ of each dilution were spotted on two different uncharged nylon membranes and RNA was immobilised with a UV Stratalinker (Stratagene, La Jolla, CA, USA). Each membrane was pre-hybridised for $1 \mathrm{~h}$ at $41^{\circ} \mathrm{C}$ in Standard buffer with formamide $50 \%(5 \times \mathrm{SSC} ; 1 / 5$ vol blocking solution, $10 \times$ concentrate, Boehringer Mannheim, Indianapolis, IN, USA; SDS $0.02 \% \mathrm{w} / \mathrm{v}$; $\mathrm{N}$-lauroylsarcosine $0.1 \% \mathrm{w} / \mathrm{v}$; deionised formamide $50 \%$ ). Probes for $f l a A$ and $u r e A$ were synthesised from PCR products which had been gel purified by the Geneclean II Kit (Bio101, Inc., Vista, CA, USA), ethanol precipitated and verified by restriction analysis. The PCR products for $f l a A$ and ure $A$ were digoxigenin (DIG)-labelled with the DIG High Prime Labeling and Detection Starter Kit I (Boehringer Mannheim) according to the manufacturer's recommendations. Each duplicate membrane prepared above was then hybridised overnight at $41^{\circ} \mathrm{C}$ in pre-hybridisation solution containing either the flaA probe $(80 \mathrm{ng} / \mathrm{ml}$ final concentration) or the ure $A$ probe $(26.4 \mathrm{ng} / \mathrm{ml}$ final concentration). Membranes were then washed, blocked, incubated with an anti-DIG alkaline phosphataseconjugated antibody for $1 \mathrm{~h}$ and detected colorimetrically according to the manufacturer's recommendations. The membranes were digitised on a Gelprint $2000 \mathrm{i}$ (Biophotonics) and spot intensities were quantified with ImageQuant software (Molecular Dynamics).

\section{Results and discussion}

Table 1 illustrates the increases in colonisation rates from the initial passage in piglets of human isolate 26695 (p0), through intermediate passages, until the final in-vivo passage used in this study $(p>20)$. These data are extensions of an earlier, more limited study that demonstrated increased colonisation with pigpassage [4]. The first increase, from p0 $\left(10^{3}\right)$ to $\mathrm{p} 1$ $\left(10^{5}\right)$ is almost certainly a reflection of the adaptation of this organism from one host to another, albeit in a similar gastric environment. What is interesting to note 
Table 1. Comparisons of strain 26695 in-vivo passage numbers, colonisation rates and ratios of flaA/ureA mRNA expression

\begin{tabular}{|c|c|c|c|c|}
\hline \multirow{2}{*}{$\begin{array}{l}\text { In-vivo } \\
\text { passages }\end{array}$} & \multirow{2}{*}{$\begin{array}{c}\text { Number of } \\
\text { piglets } \\
\text { infected/total }\end{array}$} & \multirow{2}{*}{$\begin{array}{l}\mathrm{cfu} / \mathrm{g} \text { of } \\
\text { mucosa }\end{array}$} & \multicolumn{2}{|c|}{ flaA/ureA ratios } \\
\hline & & & $\mathrm{PCR}^{\dagger}$ & dot-blot \\
\hline p0 & $8 / 11$ & $1 \times 10^{3 \ddagger}$ & $0.44(0.11)$ & 0.73 \\
\hline p1 & $8 / 8$ & $1 \times 10^{5}$ & $0.77(0.04)$ & 1.58 \\
\hline pll & $18 / 18$ & $1.7 \times 10^{6}$ & $0.88(0.07)$ & 1.72 \\
\hline $11<\mathrm{p}<20$ & $13 / 13$ & $5.6 \times 10^{6}$ & $1.42(0.62)$ & 1.42 \\
\hline $\mathrm{p}>20$ & $8 / 8$ & $2 \times 10^{7}$ & $2.40(0.60)$ & 2.59 \\
\hline
\end{tabular}

*Data include some piglets previously reported [4].

${ }^{\dagger}$ Mean (SD) for four trials.

${ }^{\ddagger}$ Colonisation in many piglets was too low to be exactly quantified, see reference [4].

is that even after this initial adaption $H$. pylori continued to improve its colonisation efficiency by $c$. $20-40 \%$ each passage. Fig. 1 illustrates the second piece of evidence which prompted this study. Although equal amounts of OMPs from laboratory-passaged and serially in-vivo passaged isolates of the same parent strain were loaded on 2-D gels, immunoblots of the OMPs demonstrated flagellar proteins as clearly prominent in the pig-passaged isolate but barely detectable in the laboratory-passaged isolate.

Fig. 2 is an example of a gel used to compare the levels of flaA mRNA present in isolates differing in in-vivo passage number. The level of flaA mRNA

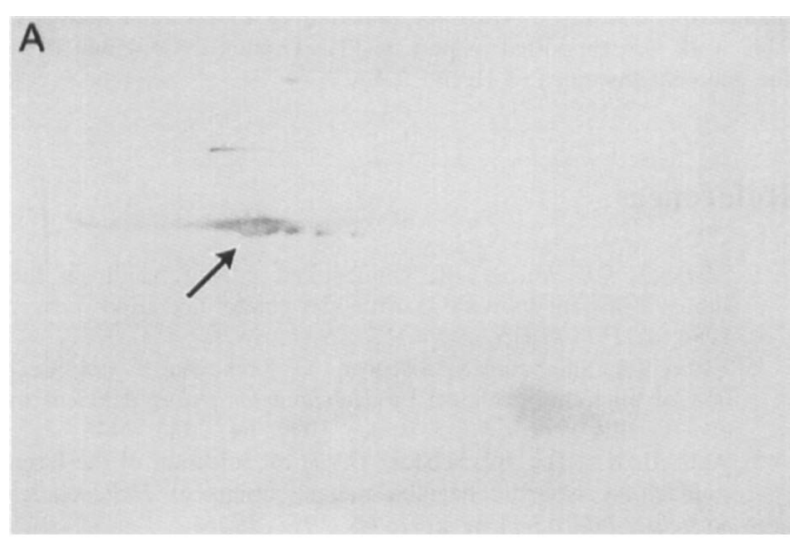

B

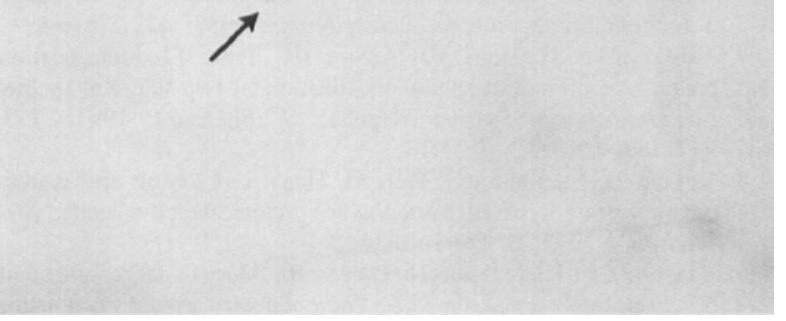

Fig. 1. Detection of flagellins in pig-passaged (A) and laboratory-passaged (B) strains by immunoblot. Similar amounts of OMPs from parent strain 26695 and an isolate that had been multiply passaged in vivo were loaded on 2-D gels. Arrows indicate the location of flagellins.

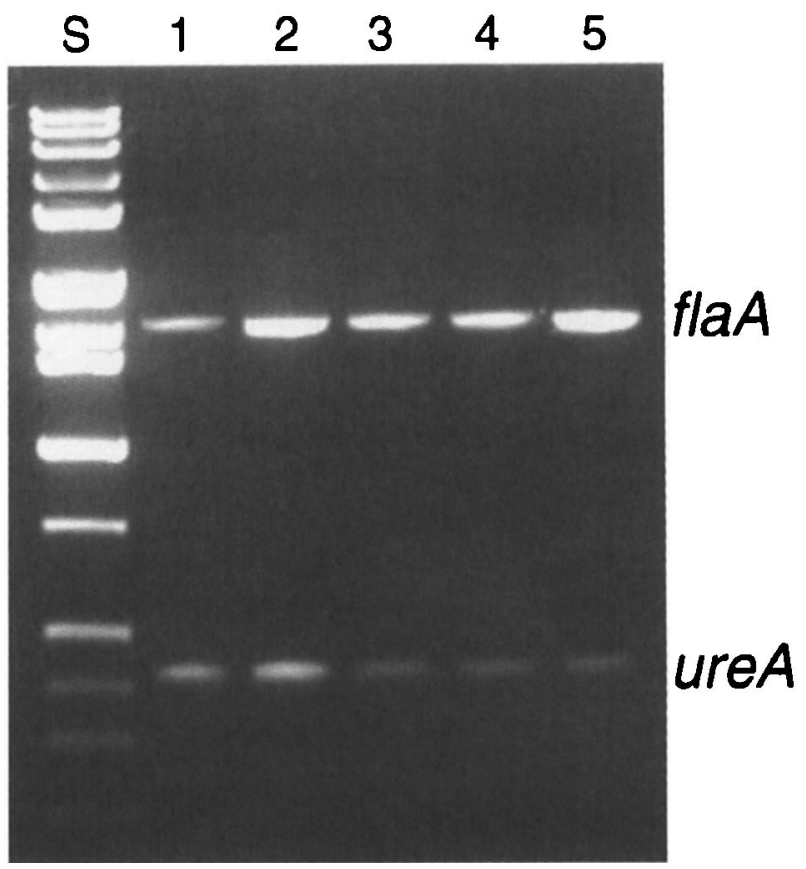

Fig. 2. A typical agarose gel comparing $f l a A$ and ureA mRNA expression levels between strains after different numbers of in-vivo passages. As the passage number increases serially (represented from left to right on the gel) the ratio of flaA to ureA mRNA increases (see Table 1). Lane S, Hi-lo DNA ladder (Minnesota Molecular, Minneapolis, MN, USA); 1, H. pylori human isolate 26695, 0 pig passages; 2, 1 passage; 3, 11 passages; 4, between 11 and 20 passages; 5, $>20$ passages.

present in each total RNA sample was expressed as a ratio to ure $A$ mRNA present in the same sample; ure $A$ is believed to be expressed constitutively [10] except, perhaps, under variable nitrogen availability [11]. As culture conditions were not varied in the in-vivo or invitro experiments, ure $A$ served as an endogenous internal control in both multiplex PCR and the dotblot analysis to compensate for any variation between samples which may have been the result of handling. For multiplex amplification, 28 was the lower limit of cycles necessary to visualise both amplicons and was used, therefore, for all amplifications. Table 1 illustrates the increase in flaA mRNA content, as determined by PCR, which occurred after multiple invivo passages. There is an approximately two-fold initial increase in flaA mRNA after the first passage in 
pigs which, like colonisation efficiency mentioned above, is related to the strain's adaptation to a new host. It is likely that a significant proportion of the laboratory-passaged human isolate, in the absence of selective pressure favouring motility, had lost its ability to synthesise flaA mRNA efficiently and was subsequently eliminated during the first passage in pigs. However, the level of flaA mRNA continued to increase incrementally well after the first passage and, at the final endpoint of $>20$ passages, the level of flaA mRNA was approximately three times greater than the level after one passage. A linear regression curve plotting the $\mathrm{cfu} / \mathrm{g}$ of mucosa against the expression ratios as determined by PCR returned a $p$ value of 0.01 (data not shown).

These data are supported by the RNA dot-blot analysis (Table 1), the RNA for which had been isolated independently from that used for the PCR analysis. There was an initial jump in the level of flaA mRNA (again expressed as a ratio to ure $A$ mRNA) after the first passage. This upward trend continued as evidenced by the ratios present after 11 passages and after $>20$ passages.

This study showed that flaA mRNA levels monitored in vitro correlated with growth in vivo and that selection for increased proliferation in piglets was associated with increased FlaA protein and increased flaA transcript levels. Previous studies have shown that phenotypic expression of motility also increases with animal passage [12], but such expression appears to be an insensitive indicator of FlaA expression. Motility expression jumped from $30 \%$ in strain 26695 to $100 \%$ motile colonisers after a single animal passage [12], while FlaA expression continued to increase with continued animal passage.

Although the basis for the increased expression of $f a A$ in in-vitro passaged strains has not yet been formally investigated, at least two possibilities seem plausible. It has been determined that the flaA gene has a sigma-28 like promoter [8] and it is possible that, with piglet passage, natural random genetic mutation alters this region such that the promoter operates with an increased efficiency. This increased efficiency may confer a selective advantage to bacteria which are able to produce more flaA mRNA and, presumably, more FlaA. Another cause may be found in the hierarchical nature of flagellar synthesis. Schmitz et al. have recently described a gene in $H$. pylori $(f b A)$, which is involved in the regulation of flagellar biogenesis [13]. It has been hypothesised that a similar membrane-associated protein in Caulobacter crescentus (FlbF) acts as a signal transducer that coordinates flagellar expression either directly or by activation of intermediate transcriptional regulators [14]. If increased levels of flaA mRNA augment the ability of $H$. pylori to colonise its host, bacteria with adaptations in this system that confer an increased ability of $H$. pylori to synthesise $f a A$ mRNA would also have a selective advantage.

It is likely that other genes besides flaA will demonstrate a correlation between transcription levels and colonisation efficiency during in-vivo passage. The increased ability of $H$. pylori to colonise may be due to varying transcription levels of a number of colonising factors. Previous studies have shown that numerous bacterial virulence factors are often regulated together [15] and subtle changes in the efficiencies of these networks may contribute to the incremental increases in colonisation efficiency which have been observed in the gnotobiotic piglet model. The data from the present study lead to the inference that events are occurring at the transcriptional level that improve colonisation rate. Components of a system which impact transcriptional levels of important motility genes may prove to be useful targets for immunisation strategies against $H$. pylori. Further studies investigating the relationships between flaA transcript levels, the mRNA levels of other genes, and their correlation to colonisation efficiencies during invivo passages will be valuable to the understanding of this nearly ubiquitous pathogen.

We thank J. Younger for expert technical assistance, Drs D. Berg, and S. Suerbaum for helpful suggestions and critical review of the manuscript, and Dr T. Trust for donation of monoclonal antibody. This work was supported in part by PHS Grant R29DK45340 from the National Institutes of Health, USA.

\section{References}

1. Marshall BJ, Warren JR. Unidentified curved bacilli in the stomach of patients with gastritis and peptic ulceration. Lancet 1984; 1: 1311-1315.

2. Eaton KA, Suerbaum S, Josenhans C, Krakowka S. Colonization of gnotobiotic piglets by Helicobacter pylori deficient in two flagellin genes. Infect Immun 1996; 64: 2445-2448.

3. Andrutis KA, Fox JG, Schauer DB et al. Infection of the ferret stomach by isogenic flagellar mutant strains of Helicobacter mustelae. Infect Immun 1997; 65: 1962-1966.

4. Akopyants NS, Eaton KA, Berg DE. Adaptive mutation and cocolonization during Helicobacter pylori infection of gnotobiotic piglets. Infect Immun 1995; 63: 116-121.

5. Tomb J-F, White O, Kerlavage AR et al. The complete genome sequence of the gastric pathogen Helicobacter pylori. Nature 1997; 388: 539-547.

6. Blaser MJ, Hopkins JA, Berka RM, Vasil ML, Wang W-LL. Identification and characterization of Campylobacter jejuni outer membrane proteins. Infect Immun 1983; 42: 276-84.

7. Kostrzynska M, Betts JD, Austin JW, Trust TJ. Identification, characterization, and spatial localization of two flagellin species in Helicobacter pylori flagella. $J$ Bacteriol 1991; 173: 937-946.

8. Leying H, Suerbaum S, Geis G, Haas R. Cloning and genetic characterization of a Helicobacter pylori flagellin gene. Mol Microbiol 1992; 6: 2863-2874.

9. Clayton CL, Kleanthous H, Coates PJ, Morgan DD, Tabaqchali S. Sensitive detection of Helicobacter pylori by using polymerase chain reaction. J Clin Microbiol 1992; 30: 192-200.

10. Collins CM, D'orazio SEF. Bacterial ureases: structure, regulation of expression and role in pathogenesis. $\mathrm{Mol}$ Microbiol 1993; 9: 907-913.

11. Cussac V, Ferrero RL, Labigne A. Expression of Helicobacter pylori urease genes in Escherichia coli grown under nitrogenlimiting conditions. J Bacteriol 1992; 174: 2466-2473.

12. Eaton KA, Morgan DR, Krakowka S. Campylobacter pylori 
virulence factors in gnotobiotic piglets. Infect Immun 1989; 57: 1119-1125.

13. Schmitz A, Josenhans C, Suerbaum S. Cloning and characterization of the Helicobacter pylori flaA gene, which codes for a membrane protein involved in coordinated expression of flagellar genes. J Bacteriol 1997; 179: 987-997.
14. Ramakrishnan G, Zhao J-L, Newton A. The cell cycleregulated flagellar gene $A b F$ of Caulobacter crescentus is homologous to a virulence locus ( $\mathrm{l} c \mathrm{rD}$ ) of Yersinia pestis. $J$ Bacteriol 1991; 173: 7283-7292.

15. Guiney DG. Regulation of bacterial virulence gene expression by the host environment. $J$ Clin Invest 1997; 99: 565-569. 